\title{
Frameworks for ICT Integration in Mathematics Education - A Teacher's Perspective
}

\author{
Appavoo Perienen ${ }^{1^{*}}$ \\ ${ }^{1}$ Open University of Mauritius, MAURITIUS \\ Received 8 August 2018 • Accepted 13 December 2019
}

\begin{abstract}
Technology holds pedagogical affordances that can help address low performance in mathematics education. This research study investigated which factors significantly contributed to technology usage by Mathematics teachers. The 155 teachers surveyed were found to be regular users of computers, demonstrating a high opinion of the pedagogical worth of technology and perceiving the tool as being useful for enhancing Mathematic education. However, only a minority was really using technology in their teaching practices. Teachers reiterated the need to be adequately trained in the pedagogical integration of Information and Communication Technology (ICT), insisted on the provision of better computer services in schools, including access to the Internet and solicited the support of parents to accompany their children in their studies. A revised theoretical model was drawn based on the Technology Acceptance Model (TAM) and unified theory of acceptance and use of technology (UTAUT) models, and the two ICT related variables that caused significant variances in technology usage were perceived ease of use and facilitating conditions.
\end{abstract}

Keywords: ICT integration, mathematics education, TAM, teachers' beliefs, UTAUT

\section{INTRODUCTION}

Teaching and learning with technology is not a new endeavour and dates back to the ancient days of television, where great expectations were formulated to transform the student's learning world (Lowyck, 2014). With the advent of computers impacting nearly all walks of life, the education sector too is witnessing a paradigm shift. Readily available computers at affordable costs have come within reach of the great majority, be it at home and/or school, and policy makers and major stakeholders are projecting hopes to see learning take a new turn. Zelkowski, Gleason, Cox and Bismark (2013) reported on the panoply of international research showing that students learn Mathematics better with effective and appropriate technology. An overall conclusion from the results is that more concrete encouragement, support and opportunities must be developed to increase teachers' motivation and thus improve the level and quality of ICT use in classrooms (Uluyol \& Sahin, 2016). Kaleli-Yilmaz (2015) investigated technology integration and reported that teachers' attitude to technology and willingness to use technology were significant factors.

Teachers channel and facilitate content learning for students, and trigger their creative mind in line with the curriculum. As technology takes an increasing role in knowledge acquisition and content assimilation and understanding, there is a pressing need to situate the technological competence of teachers, and thus their ability to meet the emerging learning styles of digital natives. Numerous research studies (Aslan \& Zhu, 2016; Bozkurt, 2016; Zelkowski et al., 2013) have focused on pre-service teachers, but it is even more crucial to look at the critical mass of practicing teachers and unveil factors that hinder or facilitate this technological uptake.

Somelch (2008) reported minimal pedagogical change, and Aslan and Zhu (2016) referred to low-level use, whereby only basic procedures like Internet information search, presentation programs and other application programs, supplement teaching practices. Within this compendium of realities and given the ubiquity of computers and their potential to impact learning, this study evaluates teachers' perceived ease of 


\section{Contribution to the literature}

- Research study investigates which factors significantly contributed to technology usage by Mathematics teachers.

- Although teachers are regular users of computers, only a minority is really using technology in their teaching practices.

- A revised theoretical model is drawn based on the Technology Acceptance Model (TAM) and unified theory of acceptance and use of technology (UTAUT) models.

use and perceived usefulness of computers, together with other factors like social influence and school computing facilities that may have an impact on technology usage.

No paradigm shift in the educational process can be successfully envisaged without teachers being the first partakers of the intention. Today there is mounting pressure on them to tap into the affordances of technology to bridge learning gaps. As gatekeepers to the classroom, what knowledge and level of comfort teachers possesses about technology will impact its integration in the class (Bingimlas, 2009; Ensminger, 2016). Shulman (1986) noted that teachers who did not learn with technology now have to be empowered to transform subject matter content through teaching strategies to make knowledge accessible to learners. Coupled with the new skills that teachers have to develop and master, is their personal beliefs about the usefulness of the technology. Fulton and Tomey-Purta (cited in McCombs, 2000, p. 10) found that it was teacher beliefs about teaching and learning and the learning community that was formed that most led to positive benefits of technology. Ertmer (1999) suggested that teachers' beliefs about technology have a greater influence on their integration of the technology than resources and other contextual factors. She also mentioned that when integrating technology into their curricula, teachers' efforts are often limited by both external (first-order) and internal (second-order) barriers, with first-order barriers dealing with the acquisition of technical skills needed to operate a computer and second-order ones dealing with pedagogical models of technology use.

According to Niess (2006), "if technology is used to improve the learning of mathematics at all levels, students will be better prepared to use technology appropriately, fluently, and efficiently to do mathematics in technology-rich environments in which they will study and work in the future."

\section{TAM and UTAUT}

Another approach towards technology acceptance and usage that has been widely adopted and researched is the technology acceptance model (TAM), based on the theory of reasoned action by Fishbein and Ajzen (1975). TAM is a theoretical framework which provides a systematic way to make predictions about technology acceptance and computer usage behaviours. This technology acceptance model rests upon the fact that the way a person perceives the usefulness (PU) of a technology and its ease of use (PEOU) will determine the way that person makes use of that particular technology (Bandura, 1982). Perceived usefulness (PU) measures the efficacy identified by the user while perceived ease of use (PEOU) identifies the difficulty level of the technology perceived by the user (Lala, 2014) and these two forms the two major components of TAM. The first proponent of TAM (Davis, 1985) based his model on the assumption that user motivation can be explained by three factors: (1) perceived ease of use, (2) perceived usefulness and (3) attitude toward usage. Davis hypothesized that the attitude of a person towards a system was a major factor that influenced whether he/she would use or reject the system. In turn, the person's attitude seems to be influenced by two major beliefs: perceived usefulness and perceived ease of use, where perceived ease of use has a direct influence on perceived usefulness.

Davis, Bargozzi and Warshaw (1989) later found that behavioural intention was yet another important component of system response and consequently it replaced the attitude construct. Furthermore, they found that perceived usefulness was a major significant determinant of peoples' intention to use computers while perceived ease of use was only a significant secondary determinant. In 1996, Venkatesh and Davis proposed a new refined model of TAM (Figure 1).

However, according to Lala (2014), there is a need for future research that can focus on developing new models that exploit the strengths of TAM because though it is a very popular model for explaining and predicting the use of a system, it does have some uncertainty among some researchers about its application and accuracy. This model has been largely reviewed by many researchers and additional factors and variables identified to include extrinsic and intrinsic motivation, self-efficacy (Bandura, 1982), behavioural intention (Davis, 1985; Davis, Bagozzi, \& Warshaw 1989), and opinion of others (Javidniaa, Nasirib, \& Kiani 2012; Svendsen, Johnsen, Almas-Sorensen, \& Vitterso, 2013), all of which were found to influence the adoption and usage of new technologies. Ensminger (2016) proposed that investigating teachers' perceptions of these variables can provide a better picture of the 


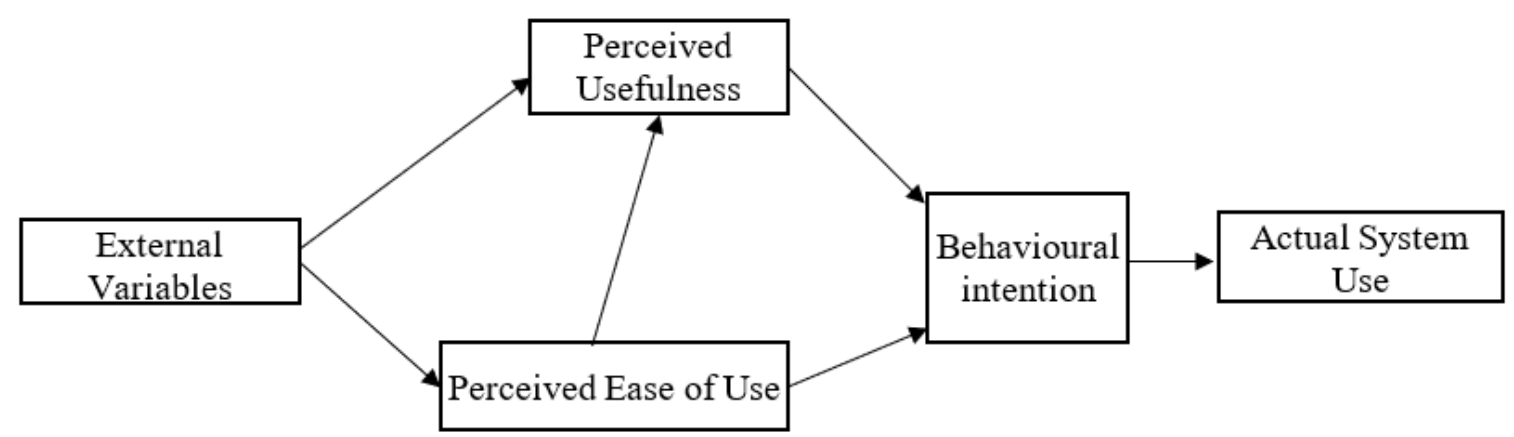

Figure 1. Final version of TAM of Venkatesh and Davis, 1996

(Source: Lala, 2014)

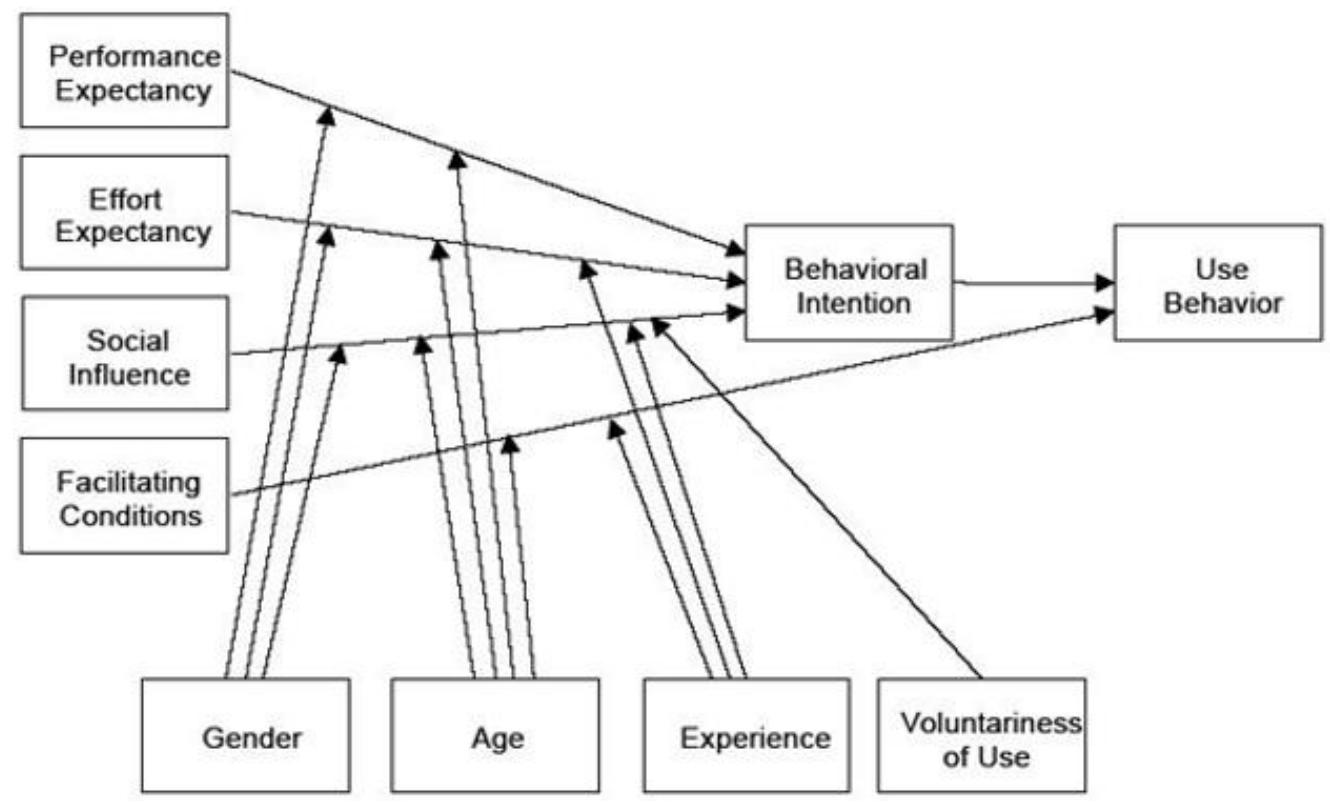

Figure 2. UTAUT

landscape that policy makers need to look at to understand the factors that influence the adoption of technology in the classroom.

Another well applied model is the Unified Theory of Acceptance and Use of Technology (UTAUT), which was developed in 2003 by Venkatesh (Lala, 2014). In Figure 2, we note the inclusion of some additional constructs compared to TAM, like voluntariness, facilitating conditions, social influence and experience which are relevant to determining use behaviour. While researchers continue to modify these models and adapt them to their particular context of investigation, the three concepts that probably cut across all others are the 'ease of use', the 'usefulness' of the technology and its 'availability.'

The environment within which teachers can effectively integrate computing tools in their teaching can largely be governed by the two models namely, TAM and UTAUT, which served as the theoretical frameworks on which this research study was run.

Literature review documents the whole set of ICTrelated and contextual variables that influence the uptake of technology in teaching. It is clear from the readings that the interplay between these variables can take different dimensions depending on the context of the study.

\section{Objectives and Research Questions}

The overarching aim of this research study is to gather the perceptions and beliefs of mathematics teachers regarding a number of issues pertaining to the uptake of ICT in schools, including their own usage of technology, the readiness of students and related predicting variables within the TAM/UTAUT frameworks. This aim has been addressed through the following research questions:

1. Are factors like gender, age, teaching experience and frequency of computer use associated with teaching mediated by technology?

2. How do teachers perceive the usefulness and ease of use of technology?

3. Which factors, social and logistics, influence teachers' uptake of technology in schools?

4. Which measures teachers reckon would improve the uptake of technology in teaching? 


\section{METHODOLOGY}

A mixed method approach, both quantitative and qualitative in nature, was adopted in the collection of data. To that effect, a questionnaire of 66 items was designed and distributed among Mathematics teachers of secondary schools from various regions. One section collected information about the profile of the respondents while other items were based on the UTAUT and TAM models. Most responses were recorded using a five-point Likert rating scale.

Through semi structured questions, more in-depth information was sought from five focus group discussions, each group comprising 5-6 teachers from different schools. These focus group discussions lasted around one hour each. This triangulation approach in data helped to complement and confirm the responses provided in the questionnaires and thus ensured reliability of the process collection (Matthews \& Ross, 2010).

The Cronbach Alpha analysis was carried out to validate the items for each of the five particular constructs as described by the TAM and UTAUT models. Other statistical analyses such as the Spearman Rho, ChiSquare, Mann Whitney and Kruskal Wallis were also performed to investigate any correlation or association between the items of the questionnaire.

Both the purposive and quota sampling techniques (Denscombe, 2013, p. 34) were adopted to reach out to the right target audience, that is both male and female teachers with a wide range of teaching experience and working in state and private schools located in both urban and rural areas.

\section{DATA ANALYSIS}

\section{Descriptive Analysis}

Two hundred questionnaires were distributed to teachers, working in 44 secondary schools, located in both urban and rural areas of Mauritius. One hundred and fifty-five of them successfully completed the questionnaires. There was a slightly higher percentage $(58.7 \%)$ of male teachers. Teachers in all age groups participated in the survey, with however $65 \%$ of them being younger than 40 . Sixty-eight percent of teachers were from private schools. Respondents with quite a wide range of teaching experience participated in the survey. Sixty percent rated their ICT skills as good or excellent. This explains why $71.6 \%$ teachers were using the computer daily.

Only $12 \%$ respondents used technology in $25 \%$ or more of their teaching. Most respondents (83\%) had a professional teaching qualification, hence making the sample very appropriate to provide data on pedagogical matters involving ICT integration which is now an integral component of any teaching training curriculum.

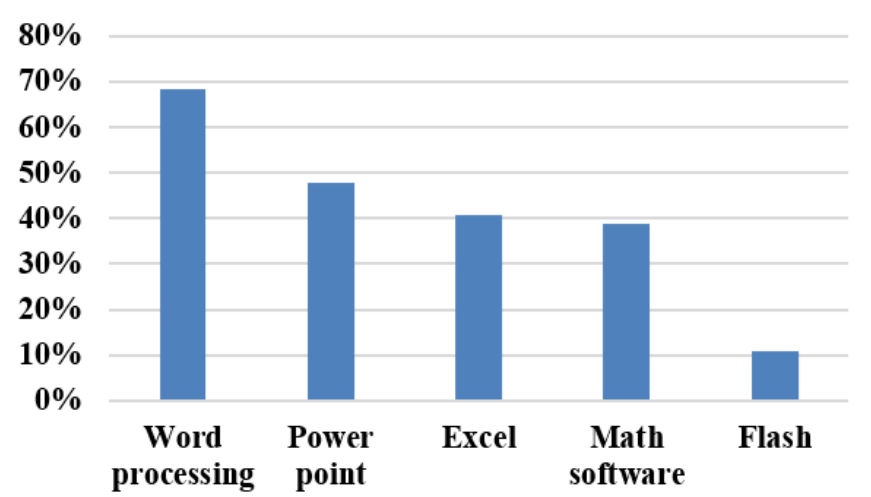

Figure 3. Types of software use

\section{Applications Programs Used}

Figure 3 shows that Microsoft Word (68.4\%) was the most commonly used application software. The PowerPoint presentation program was ranked second, revealing that approximately 1 out of 2 teachers was using this software. Coupled with the fact that 38.7\% reported they were using a Math software, this indicated teachers' attempt or willingness to integrate ICT in their teaching. However, despite this familiarity with technological tools, $60.6 \%$ teachers reported using technology in less than $10 \%$ of their teaching. Only $25.8 \%$ of them were supplementing $10-25 \%$ of their teaching with technology. The range of responses provided by teachers also stemmed from the ambiguity of what technology integration means. Aslan and Zhu (2016) made mention of low level or basic level of ICT integration where computers are used only to type lesson plans, present pdf version of existing materials on the screen or still to passively view an instructional video.

\section{Perceived Ease of Use}

Teachers found computers relatively easy to use, with high percentages of "strongly agree" and "agree" combined for nearly all the questions (Figure 4). Teachers $(89 \%)$ revealed they were comfortable working with computers, choosing appropriate software for a given task (79\%), and easily transferring data among computer devices. Seventy-five percent of teachers had no difficulty learning new features of a software. The only difficulty for teachers $(68 \%)$ was their inability to deal with computer-related problems. This ease of use, as demonstrated by teachers can be a strong asset to direct their computer skills for pedagogical empowerment.

\section{How ICT Influences Learning}

Tens items were used to measure teachers' perceived usefulness of computers to impact learning (Figure 5). Data collected indicated a very high percentage of teachers (97\%) who believed that the Internet was a vast resource of useful information and that computers were 
Difficult to find documents on the computer

Easy to learn new features of a software

Computer problems cause frustration

Easily select a particular computer program for a task

Easily transfer data between computer programs

Comfortable working with computers

Know basic computer skills

No difficulty in operating computer hardware
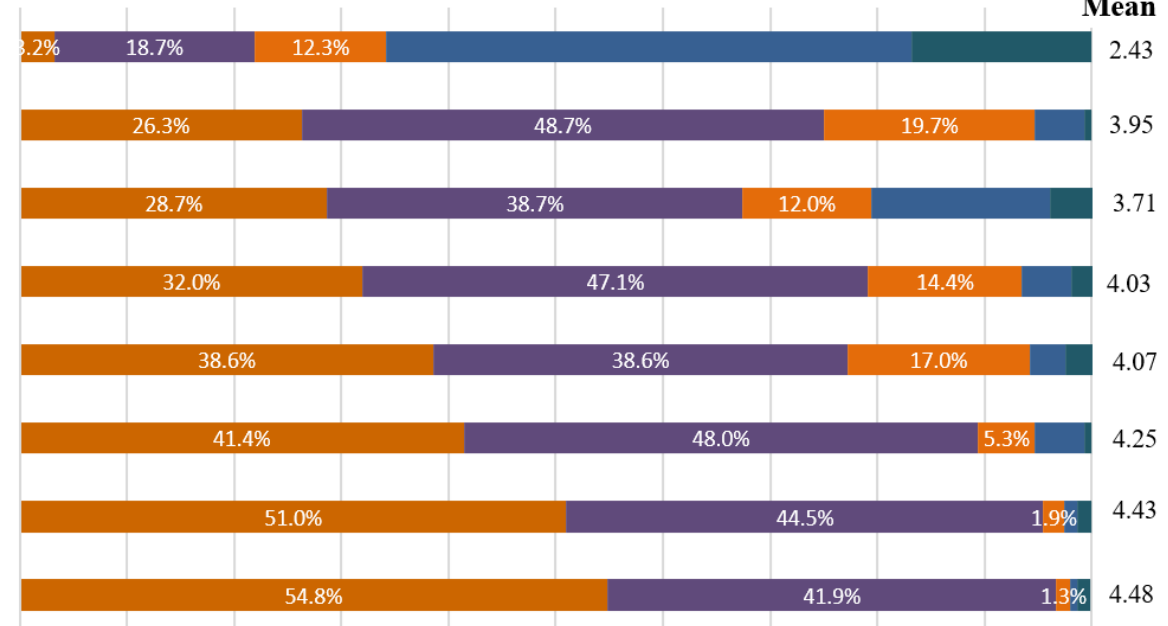

$\begin{array}{llllllllllll}0 \% & 10 \% & 20 \% & 30 \% & 40 \% & 50 \% & 60 \% & 70 \% & 80 \% & 90 \% & 100 \%\end{array}$

atrongly agree (5) $\quad$ Agree (4) $\quad$ Not sure (3) $\quad$ Disagree (2) $\quad$ Strongly disagree (1)

Figure 4. Perceived Ease of Use (PEOU)

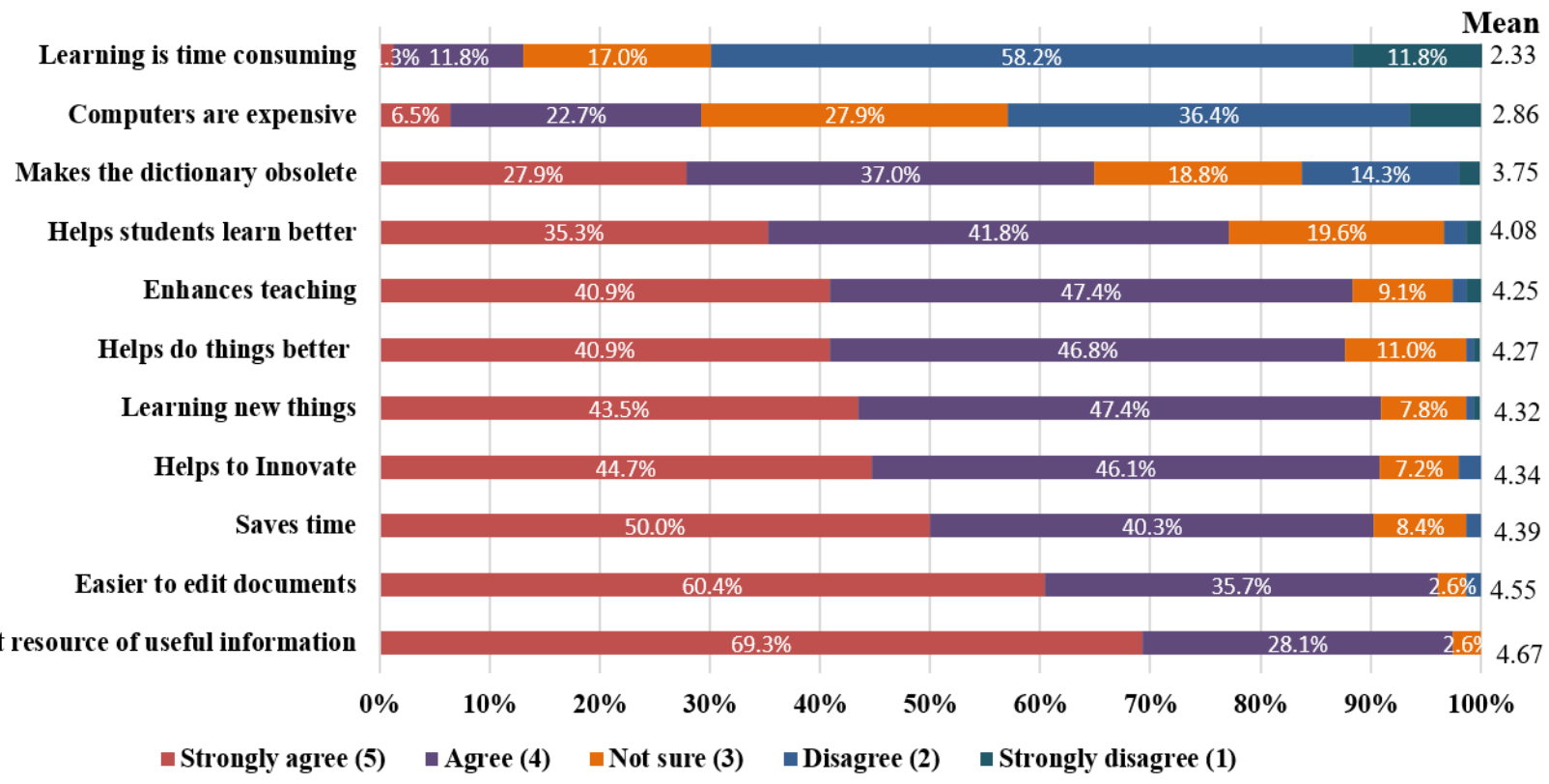

Figure 5. How ICT influences learning

Internet- vast resource of useful information

convenient to prepare and edit documents. According to the majority of teachers, ICT helped to save time, innovate, learn new things and do things better. A large majority $(88.3 \%)$ of teachers opined that teaching could be enhanced with ICT. Unfortunately, this belief was not translated into real classroom practices as only $12 \%$ of them actually used ICT in $25 \%$ or more of their teaching. Seventy-seven percent agreed that students could learn better with computers. This revealed that teachers were very positive about the potential of technology to impact learning as reported by different scholars (Enayati, Modanloo, \& Kazemi 2012; Yalcin, Kahraman, \& Yilmaz 2011). Some $13 \%$ of teachers believed that learning with computers is time consuming, a finding which concurs with that of Karagiorgi and Charalambous (2004 cited in Kaleli-Yilmaz, 2015).

\section{Influenced of Social Factors on Computer Usage}

Five items measure how social factors influenced teachers' use of technology (Figure 6). The majority of teachers $(74 \%)$ reported that friends and colleagues contributed to enhance their computer usage. Fifty-six percent agreed that the support of rectors can be a motivation for them to use technology for teaching. This finding is in line with that of Ensminger (2016) who purported that this organizational factor often requires an intervention from administration. Forty percent of teachers felt that the opinion of other people about their computer usage was important. Whitehead, Jensen and Boschee (2003) suggested the introduction of flexible scheduling to allow teachers to meet together to plan and share experiences or gain assistance from more advanced practitioners of technology integration. Social 


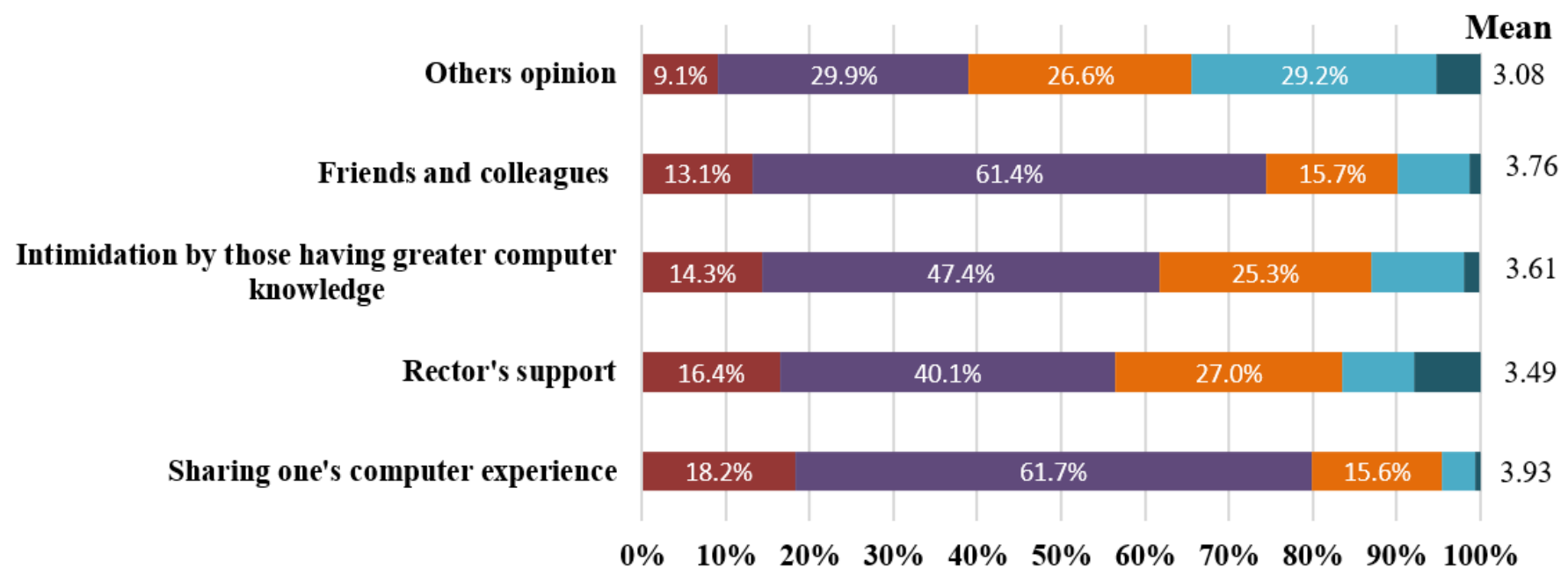

घ Strongly agree (5) $\quad$ Agree (4) $\quad$ Not sure (3) $\quad$ Disagree (2) $\quad$ Strongly disagree (1)

Figure 6. Influence of social factors on computer usage

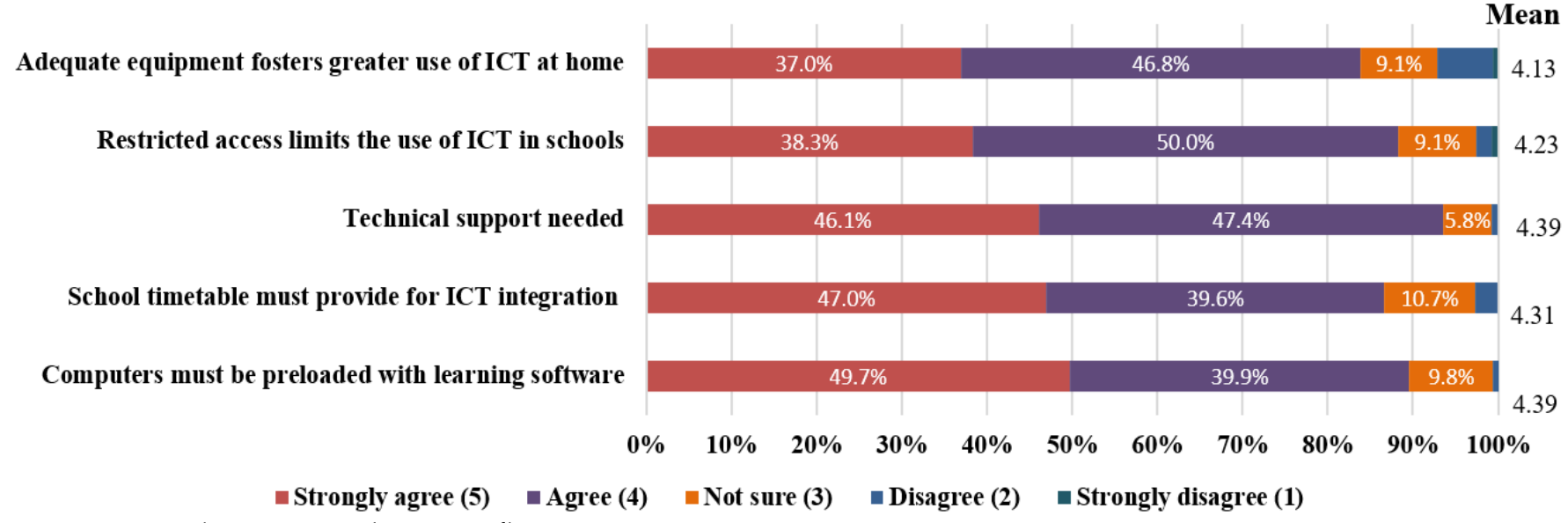

Figure 7. Facilitating conditions influencing computer usage

influence, including management's support and teachers' interaction, was thus identified as a strong motivational factor for teachers' eventual uptake of technology in their profession.

\section{Facilitating Conditions Influencing Computer Usage}

Around $90 \%$ of teachers opined that computers in schools must already be preloaded with the appropriate learning software and believed that technical support is a must to facilitate computer usage at school (Figure 7). Around a similar percentage $(87 \%)$ wished that the school time-table could make provision for integration of ICT in teaching and learning. Teachers (84\%) used computers at home more often than in schools where the lack of adequate facilities limited the integration of ICT. Data therefore confirmed the willingness of teachers to make use of technology, provided they were equipped with the right hardware, had the necessary technical support and had access to the required learning software. Having the right facilitating conditions thus proved to be a key factor for the effective use of computers as mentioned by Bingimlas (2009).

\section{Practices which Translate the Acceptance of Technology}

This construct, which was measured by eight items (Figure 8), yielded a Cronbach alpha value of 0.884 and hence reliably evaluated the technology usage by teachers based on various practices. Data revealed that $89 \%$ of teachers were prepared to use ICT provided they were given the right training and given opportunities to do so. Sixty one percent confirmed using ICT to record students' information including marks. Use of the computer for exchanging documents was reported by only $42 \%$ of teachers. Many teachers reported frequent use of technology for teaching practices like lesson preparation and searching the Internet for new teaching methodologies and materials. But the overarching revelation of this section of the questionnaire points to the limited number $(18 \%)$ of teachers making frequent use of ICT for direct teaching. This explains that willingness on the part of teachers, was there but real integration of ICT in teaching was very limited. Data thus showed that teachers made out the difference 


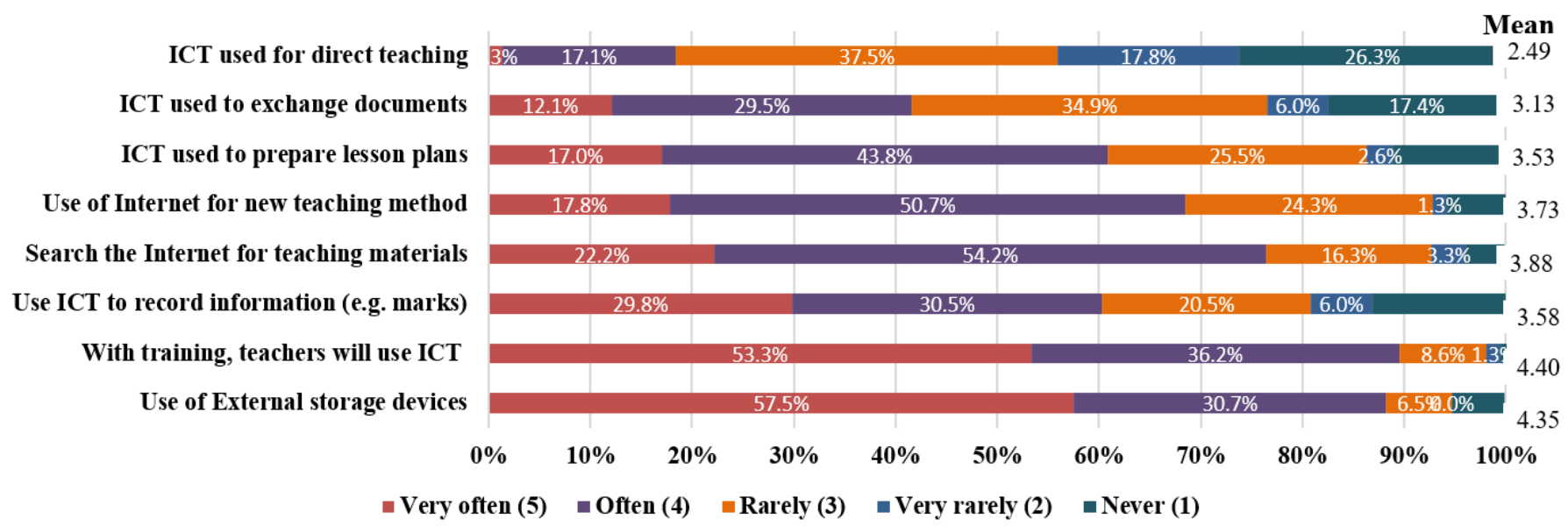

Figure 8. Practices which translate the acceptance of technology

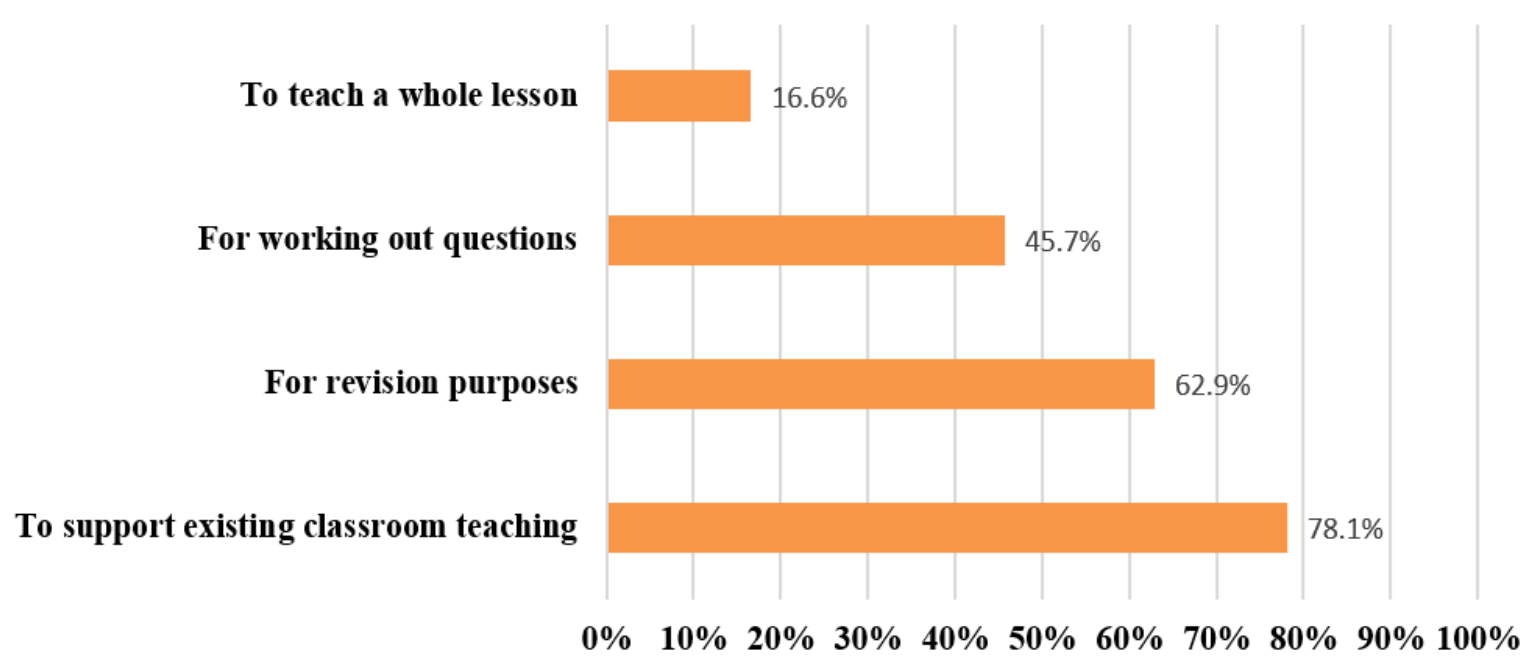

Figure 9. How technology enhances teaching

between the tool as a support in the teaching profession and used it for direct teaching.

\section{How Technology Enhances Teaching}

From Figure 9, we observe that teachers believed ICT could support existing pedagogical approaches in schools; for example, to complement classroom teaching and support revision. In the focus group discussions teachers made mention of instructional videos which can be viewed at leisure by students at any given time and even at home, hence adopting the flipped classroom concept (Estes, Ingram, \& Lin, 2014).

Around $48 \%$ of teachers believed ICT could provide the right medium for students to work out questions, thus helping to augment or consolidate theoretical understanding. Computers can generate different sets of questions from a database for practice. Only seventeen percent of teachers believed a whole lesson could be entirely taught using ICT. This is consistent with a previous finding which revealed that only $18 \%$ of teachers reported using computers for direct teaching.

The above findings allude to teachers' unpreparedness despite their strong willingness to transit to computer-based teaching environment. So, positive attitude must be accompanied by technologyintegration skills and provision of adequate computer facilities within the school environment.

\section{Bivariate and Inferential Statistics}

Gender Bias. A Chi-square test revealed no gender bias in the responses provided by the respondents which means that both male and female teachers shared more or less the same working experience with technology like, frequency of use, level of computer skills and percentage of technology-based teaching.

Age factor. Age was found to have moderate (Cramer $\mathrm{V}=0.234)$ effect on computer skills $\left(\chi^{2}(6)=16.81, \mathrm{n}=153\right.$, $\mathrm{p}=0.010$ ). The post hoc tests revealed that the difference was particularly significant between the young (age 2030) and old (age > 50) teachers, with the latter demonstrating lower computer skills. Use of computers being linked to level of computer skills, it was thus expected that age would also account for differences in frequency of computer use $(\chi 2 \quad(6)=13.13 n=153$, $\mathrm{p}=0.041$ ), with a slightly lower effect size (Cramer V= 0.207 ). The younger teachers once again demonstrated more frequent use of computers. 
Table 1. Interplay of ICT-related and other factors

\begin{tabular}{llllll}
\hline & $\mathbf{1}$ & $\mathbf{2}$ & $\mathbf{3}$ & $\mathbf{4}$ & $\mathbf{5}$ \\
\hline PEOU & $X$ & $\sqrt{ }$ & $\sqrt{ }$ & $\sqrt{ }$ & \\
PU & $\sqrt{ }$ & $\sqrt{ }$ & $\mathrm{X}$ & $\mathrm{X}$ & $\mathrm{X}$ \\
SI & $X$ & $\sqrt{ }$ & $X$ & $X$ & $X$ \\
FC & $X$ & $X$ & $X$ & $X$ & $X$ \\
TU & $X$ & $\sqrt{ }$ & $\sqrt{ }$ & $\sqrt{ }$ \\
\hline
\end{tabular}

X- no impact $\sqrt{ }$ - significant impact

1 - Gender 2 - Age 3 - Level of computer skills 4- Frequency of computer use 5 - Teaching experience

Computer skills factor. The association of computer skills was found to be significant with the frequency of computer use $\left(x^{2}(4)=13.57, n=151, p=0.009\right)$, percentage of teaching involving technology $\left(\mathrm{x}^{2}(6)=22.56, \mathrm{p}=0.001\right.$, $n=153)$ and teaching experience $\left(X^{2}(8)=19.88, n=150\right.$, $\mathrm{p}=0.011)$. There was a medium effect size of levels of computer skills on computer use (Cramer's V= 0.212) and on the percentage of teaching done using technology (Cramer's V $=0.272$ ). Post hoc tests were carried out to evaluate pairwise differences among the three levels of computer skills, namely "satisfactory", "good" and "excellent". Type I error was controlled across all tests by using the Bonferroni approach. The results of these tests revealed that computer skills and hence frequency of computer use were at a higher level among those with less teaching experience, that is younger teachers. It was worth noting that percentage of teaching using technology was not associated with the frequency of computer use. So, teachers, even if they were frequent computer users indicated 'no use' or 'very low use' of computers in their teaching. This would imply that teachers were using computers more for personal rather than professional reasons.

This section of the data analysis led to the modelling of a theoretical framework that describes those factors that influenced technology uptake in the teaching of Mathematics. It was observed that the most impacting element for technology integration was the level of computer skills mastered by teachers, which is in turn was influenced by their age and experience. But, computer skills also had a bearing on how frequently teachers used computers although that frequency had no significant impact on the percentage of ICT used for teaching. Boosting the computer skills of teachers through sustained training and professional development can therefore lead to greater computer use and hence more technology-driven teaching.

\section{Impact of Numerous Factors on the Five Constructs of TAM}

The main purpose of this research study was to evaluate technology usage by Mathematics teachers within the TAM and UTAUT theoretical frameworks. The following five constructs namely Perceived Ease of Use (PEOU), Perceived Usefulness (PU), Social Influence (SI), Facilitating Conditions (FC) and Technology Usage (TU) were measured using responses from 33 items.
The calculated Cronbach values for the different constructs were nearly all above 0.75 , thus confirming the reliability of the items used to measure the abovementioned constructs, safe for the items of the SI construct which has a slightly lower value. On a scale of 1 (strongly disagree) to 5 (strongly agree), PEOU ( $\mu=$ 4.06) and FC, $(\mu=4.3)$ were rated the highest, hence giving a first indication that teachers agreed on the ease of use and the value of facilitating conditions in the decision to use ICT in teaching.

As at date, research has mostly focused on the five constructs and the association among them with little attention to the possible influence of other variables. One aspect of this research work was precisely to identify if factors like gender, age, computer skills, frequency of computer use, teaching experience had any impact on the five constructs of the TAM framework namely PEOU, PU, SI, FC and TU. Table 1 summarizes this impact and shows that all factors, safe gender, had an influence particularly on two of the five constructs namely the PEOU and TU constructs. Age, however, did have an influence on PU and SI too.

The next subsections describe the impact of the different variables like gender, age, level of computer skills, frequency of computer use and teaching experience on each of the five constructs.

Gender factor. The Mann Whitney tests revealed a significant bias regarding $P U(U=1902, p=0.03)$, hence showing that male teachers gave a higher rating for perceived usefulness. On account of this difference male teachers might be more inclined to integrate computers in their teaching. Gender accounted for $24.4 \%$ of variability in PU, which is quite significant.

Age factor. A Kruskal Wallis test was carried out and revealed that age impacted significantly on PEOU $\left(\chi^{2}(4\right.$, $\mathrm{N}=155)=15.05, \mathrm{p}=0.005), \mathrm{PU}\left(\chi^{2}(4, \mathrm{~N}=149)=10.03\right.$, $\mathrm{p}=0.04)$, SI $\left(\chi^{2}(4, \mathrm{~N}=152)=14.73, \mathrm{p}=0.005\right)$ and TU $\left(\chi^{2}(4\right.$, $\mathrm{N}=144)=17.74, \mathrm{p}=0.001)$. Follow- up tests were carried out to evaluate pairwise differences among the five age groups $(<30,30-40,40-50,50-60$ and $>60)$. The results revealed that the differences for all four constructs were particularly significant between the lowest and highest age groups. Based on Cohen's (1988) set of descriptors effect size magnitude for age impact on both PEOU $\left(r^{2}=0.203\right)$ and TU $\left(r^{2}=0.257\right)$ was average. This shows that the younger generation found it easier to use technological tools, made greater use of them in their 


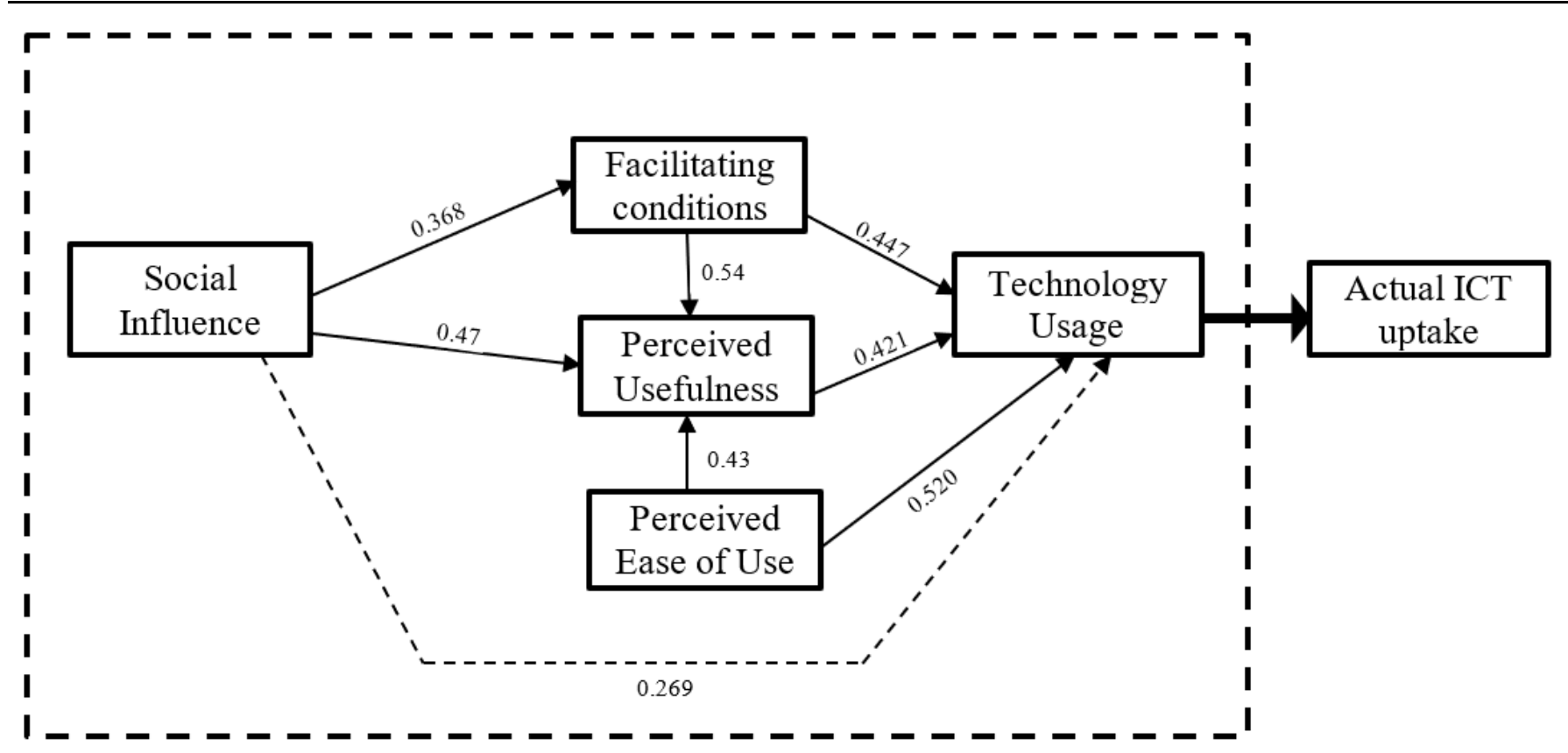

Figure 10. TAM reviewed

teaching and valued more the influence of colleagues and friends in their uptake of technology.

Computer skills factor. Analysis revealed that computer skills were associated with the constructs of PEOU $\left(X^{2}(3, N=153)=46.724, p=0.000\right)$ and technology usage $\left(X^{2}(3, N=142)=24.11, p=0.000\right)$. Follow up tests were carried out to evaluate pair-wise differences among the four levels (Excellent, Good, Satisfactory and Low). Mann Whitney $U$ tests across all possible combinations revealed that teachers with higher levels of computer skills had more positive opinions of the ease of computers and likewise demonstrated greater use of technology in their activities. The computer skills factor had a large effect size for PEOU $\left(r^{2}=0.4\right)$ and a moderate effect size $\left(r^{2}=0.28\right)$ for technology usage when comparing the groups with the lowest and highest computer skills.

Frequency of computer use factor. Kruskal Wallis tests revealed that different levels of frequency use had a significant impact on both Technology Usage $\left(X^{2}(4\right.$, $\mathrm{N}=144)=33.11, \mathrm{p}=0.000)$ and Perceived Ease of Use $\left(\chi^{2}\right.$ $(4, \mathrm{~N}=155)=19.80, \mathrm{p}=0.001)$. The more frequently teachers used computers, the higher they perceived them as easy to use and did in fact make more use of them in their teaching. After carrying out pairwise Mann Whitney tests it was revealed that significant effect sizes were observed mainly between the most frequent and less frequent users.

Teaching experience factor. The constructs of PEOU $\left(\chi^{2}(4, N=152)=13.97, p=0.007\right)$ and technology usage $\left(\chi^{2}\right.$ $(4, \mathrm{~N}=141)=11.08, \mathrm{p}=0.026)$ were found to be significantly associated with teaching experience as revealed by the Kruskal Wallis tests. Follow up tests were carried out to evaluate pair-wise differences among the five levels ( $<5$ years, $5-10$ years, $10-15$ years, $15-20$ years and $>20$ years). The differences for PEOU and TU were significant when comparing teachers with less than five years and those with more than twenty years of experience. This finding shows that those who had been in the teaching profession for a longer time were making less use of technology in their teaching as they did not perceive it as easy to use as their younger colleagues.

\section{Development of a Theoretical Model}

In this section, multivariate analyses were carried out to determine the correlations among the five constructs. Working on the TAM and UTAUT models proposed by Venkatesh, Morris, Davis and Davis (2003), the author proceeded to propose a revised theoretical framework around which technology usage by mathematics teachers could best be described. Figure 10 shows how different ICT-related variables relate to each other and most importantly to technology usage as the ultimate dependent variable under investigation.

Spearman Rho correlation values (Figure 10) indicate that the dependent variable TU was moderately associated with FC, PU and PEOU, the last one having the highest $R$ value. This confirms that PU, PEOU and FC were the three most important determinants of TU, as reported in literature (Lala, 2014). PU and PEOU can be direct outcomes of ongoing training and professional development and by increasing teachers' satisfaction and motivation to use modern technologies (Bingimlas, 2009). But, contrary to previous models, PEOU seemed to be the primary significant determinant while PU a secondary determinant.

Lala (2014) was right to mention that these models will continuously be modified and adapted depending on circumstances. SI also revealed to be a vital component of the system response and analysis showed 


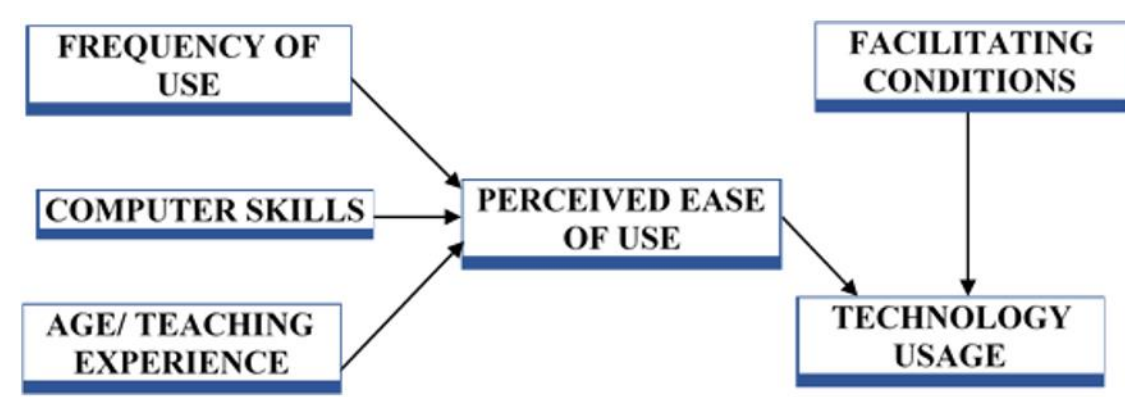

Figure 11. Teacher Integration Model

that it had the most significant impact on PU. So, interaction, discussion and support from colleagues can help teachers perceive the usefulness of the tool. Facilitating conditions were moderately associated with perceived usefulness and technology usage. During the focus group discussions, this vital element was more than once raised by teachers as they requested for better infrastructure and logistics. Ensminger (2016) and Bingimlas (2009) reported that technology integration can only be successful if schools can ensure they have, or can install, the appropriate infrastructure, and this goes beyond the actual technology itself and incorporates supporting environment like adequate space, desks, tables, room configurations, electric wiring and outlets and Internet services.

In order to probe further into the prediction of technology usage by other constructs, multiple linear regression models were generated by the SPSS software. After a few runs the most appropriate model revealed that TU was a function mostly of PEOU and FC, as per the equation given below:

$$
T U=0.761 \text { PEOU }+0.355 F C-1.004
$$

So, the two ICT-related variables that had the greatest impact on technology usage, were PEOU and FC. The regression model accounts for $48 \%$ of variances in technology usage which is a fairly high value and thus the model adequately describes the relationship between these three constructs. SI and PU were not identified as significant determinants, nor as moderating or mediating variables. This multiple regression model points to the fact that teachers must be trained to perceive technology as easy tools to use and tools which in turn must be readily available in schools.

Based on all these findings, a teacher integration model (TIM) is hereby proposed and includes other variables, which together contribute to the uptake of technology by teachers. The model shows the interconnection between all the variables and depicts the leading pathways to the use of technology in teaching.

In this model (Figure 11), the two most significant factors directly impacting TU are FC and PEOU, the latter one having the greatest influence as per the multiple regression equation (1). PEOU in turn is determined by frequency of use, teacher experience and computer skills which in turn are associated with age and experience.

This model suggests that the more teachers perceived computers as easy tools, the more likely they would integrate them in their teaching. Furthermore, TU can further be enhanced as better computer facilities are provided in schools. In order to enhance the PEOU index, this model suggests boosting the computer skills of teachers and encourage them, especially the elder ones to be more frequent users of computers. If on one hand this research study confirms the appropriateness of such models to investigate technology integration in our schools, yet it adds significant discourse to existing literature in that the intertwining of factors can take different schemas depending on the particular environment in which research is being carried. In trying to reconcile this model with previous ones, where PU was the most significant factor, the author compared responses to the items of the construct TU with another item of the questionnaire which investigated the percentage of teaching done using ICT. He concluded that there is a need to review the concept of ICT integration, how it is interpreted by different parties, and therefore, how it can be best defined. The construct technology usage was measured using items which did not expressly and totally mean direct teaching, but rather teacher-related activities like preparing lesson notes and class tests, keeping students' records and surfing the Internet for innovative teaching methodologies. Hence direct teaching using ICT has yet to be redefined and explained so that teachers can better respond to the concept of technology integration and thus help to draw a more accurate picture of its implementation in our schools.

\section{Focus Group Discussions}

The emerging themes of the focus group discussions were teacher training needs, provision and access to appropriate technological infrastructure, parental support, learners' low level of mathematics skills, often related to language barrier and mismatch between primary and secondary teaching styles. Most of these themes have been reported in the sections above and therefore the FDG proved to be an appropriate technique to confirm the reliability of the findings derived so far. 


\section{CONCLUSION AND RECOMMENDATIONS}

This study confirmed that Mathematics teachers were regular users of technology. Many of them went beyond personal use and channeled their computer skills to facilitate or improve their teacher-related activities, like word processing their lesson plans and examinations papers, recording students' marks and browsing the Internet for innovative teaching methodologies. Such computer-based activities are often interpreted as ICT usage, but technology integration spans over other implications and includes using appropriate computing tools like PCs, laptops, tablets, OHP and the like to explain, discuss and exemplify mathematical concepts. Despite the technological know-how demonstrated by a majority of teachers, there was still apprehension, hesitation and anxiety to venture into innovative computer-mediated teaching and break away with traditional practices. Balanskat, Blamire and Kefala (2006) argue that although educators appear to acknowledge the value of ICT in schools, difficulties continue to be encountered during the process of adopting these technologies.

Based on the TAM and UTAUT theoretical frameworks, this research study investigated which factors significantly contributed to the uptake of technology by Mauritian Mathematics teachers. Responses in general were not gender biased, hence, both male and female teachers shared more or less the same opinions and views about ICT integration. Computer skills, more than other variables like years of teaching experience and social influence, had a significant association with Perceived ease of use and Technology Usage. In fact, the younger generation, with a better mastery of such skills, demonstrated a higher level of technology usage. This research study, therefore confirms that TAM and UTAUT are appropriate theoretical frameworks within which the perception of teachers can be evaluated in view of an effective integration of technology in schools.

A new theoretical model thus emerged from the findings and depicted the major associations among ICT-related variables and other factors that influenced the effective uptake of technology in teaching and learning. Perceived ease of use and facilitating conditions were the two most influential factors impacting technology integration.

The very first recommendation emerging from this study is that teachers should be empowered to model their pedagogies on technological affordances, thus helping them to tap into acquired computer skills to enhance existing classroom practices. In a first phase implementation, fully equipped classrooms should be readily available for technology-based teaching. Moreover, the necessary learning software should be preloaded on the machine, and relevant instructional guidelines and worksheets where appropriate, be provided to both teachers and students. This whole implementation process should cater for a blended approach which would retain some traditional practices.

Another important recommendation concerns the introduction of e-assessment which would reconcile assessment procedures with teaching practices. E-tests in the form of computer-generated questions can be administered at any time and marking grades obtained instantaneously. This would be a great motivation for both teachers and students. There is also a need to promote an IT culture within the school by encouraging collaborative working sessions among teachers to share not only expertise, but also doubts and apprehensions. Social influence as shown in this research can contribute enormously, especially in the initial phases of implementation.

\section{REFERENCES}

Aslan, A., \& Zhu, C. (2016). Investigating variables predicting Turkish pre-service teachers' integration of ICT into teaching practices. British Journal of Educational Technology, 48(2), 552-570. https:/ / doi.org/10.1111/bjet.12437

Balanskat, A., Blamire, R., \& Kefala, S. (2006). A review of studies of ICT impact on schools in Europe: European Schoolnet. Retrieved from http://ec.europa.eu/ education/pdf/doc254_en.pdf

Bandura, A. (1982). Self-Efficacy Mechanism in Human Agency. American Psychologist, 37(2), 122-147. https:/ / doi.org/10.1037/0003-066X.37.2.122

Bingimlas, K. A. (2009). Barriers to the successful integration if ICT in teaching and learning environments: A review of the literature. Eurasia Journal of Mathematics, Science and Technology Education, 5(3), 235-245. https:/ / doi.org/10.12973/ ejmste/75275

Bozkurt, G. (2016). Mathematics teachers and ICT: Factors affecting pre-service use in school placements. International Journal of Research in Education and Science, 2(2), 453-468. https:/ / doi.org/10.21890/ijres.16161

Cohen, J. (1988). Statistical power analysis for the behavioural sciences (2nd ed.). Hillsdale NJ: Erlbaum.

Davis, F. (1985). A technology acceptance model for empirically testing new end-user Information systems: theory and results. MIT Sloan School of Management: Cambridge.

Davis, F. D., Bagozzi, R. P., \& Warshaw, P.R. (1989). User acceptance of computer technology: A comparison of two theoretical models. Management Science, 35(8), 982-1003. https://doi.org/10.1287/mnsc.35. 8.982

Denscombe, M. (2013). The Good Research Guide (4th ed.). Open University Press. 
Enayati, T., Modanloo, Y., \& Kazemi, F.S.M. (2012). Teachers' attitudes towards the use of technology in education. Journal of Basic and Applied Scientific Research, 2(11), 10958-10963.

Ensminger, D. C. (2016). Technology Planning in Schools. In N. Rushby, \& D. W. Surry (Eds.), The Wiley Handbook of Learning Technology (p. 461). John Wiley \& Sons, Inc. https://doi.org/10.1002/ 9781118736494.ch24

Ertmer, P. A. (1999). Addressing First- and SecondOrder Barriers to Change: Strategies for Technology Integration. Educational Technology Research and Development, 47(4), 47-61. https:/ / doi.org/10.1007/BF02299597

Estes, M., Ingram, R., \& Lin, J. C. (2014). A review of Flipped Classroom Research, Practice and Technologies. International Higher Education Teaching and Learning Association, 4. Retrieved from www.Hetl.org

Fishbein, M., \& Ajzen, I. (1975). Belief, attitude, intention and behaviour: An introduction to theory and research. Reading, MA: Addison-Wesley.

Javidniaa, M., Nasirib, S., \& Kiani F.J. (2012). Identifying factors affecting acceptance of new technology in the industry using hybrid model of UTAUT and FUZZY DEMATEL. Management Science Letters, 2. Retrieved from http:/ / www.growingscience.com/ msl/Vol2/msl_2012_196.pdf

Kaleli-Yilmaz, G. (2015). The Views of Mathematics Teachers on the Factors Affecting the Integration of Technology in Mathematics Courses. Australian Journal of Teacher Education, 40(8). https:/ / doi.org/10.14221/ajte.2015v40n8.8

Lala, G. (2014). The Emergence and Development of the Technology Acceptance Model (TAM). Marketing from Information to Decision, 7, 149-160.

Lowyck, J. (2014). Bridging learning theories and technology-enhanced environments: A critical appraisal of its history. In Handbook of research on educational communications and technology (pp. 3-20). New York: Springer. https:/ / doi.org/10.1007/9781-4614-3185-5_1

Matthews, B., \& Ross, L. (2010). Research Methods. New York, NY: Pearson Longman.

McCombs, B.L. (2000). Assessing the Role of Educational Technology in the Teaching and Learning Process: a learner-centered perspective. Paper presented at Secretary's Conference on Educational Technology: measuring the impacts and shaping the future,
Washington, DC, 11-12 September. ERIC Document Reproduction Service, ED 452830.

Niess, M. L. (2006). Guest Editorial: Preparing teachers to teach Mathematics with technology. Contemporary Issues in Technology and Teacher Education, 6(2). Retrieved from http://www.cite journal.org/vol6/iss2/mathematics/article1.cfm

Shulman, L. S. (1986). Those Who Understand: Knowledge Growth in Teaching. Educational Researcher, 15(2), 4-14. https://doi.org/10.3102/ 0013189X015002004

Somelch, B. (2008). Factors affecting teachers' pedagogical adoption of ICT. In J. Voogt, \& G. Knezek (Eds.). International Handbook of Information technology in primary and secondary education (pp. 449-460). New York, NY: Springer.

Svendsen, G. B., Johnsen, J. K., Almas-Sorensen, L., \& Vitterso, J. (2013). Personality and technology acceptance: the influence of personality factors on the core constructs of the technology acceptance model. Behaviour \& Information Technology, 32(4), 323-334. https://doi.org/10.1080/0144929X.2011. 553740

Uluyol, C., \& Sahin, S. (2016). Elementary school teachers' ICT use in the classroom and their motivators for using ICT. British Journal of Educational Technology, 47(1), 65-75. https:/ / doi.org/10.1111/bjet.12220

Venkatesh, V., Morris, M.G., Davis, F. D., \& Davis, G.B. (2003). User Acceptance of Information Technology: Toward a Unified View. MIS Quarterly, 27, 425-478. https://doi.org/10.2307/ 30036540

Whitehead, B. M., Jensen, D. F., \& Boschee, F. (2003). Planning for Technology: A Guide for School Administrators, Technology Coordinators, and Curriculum Leaders. Thousand Oaks: Corwin Press.

Yalcin, S. A., Kahraman, S., \& Yilmaz, Z. A. (2011). Primary school teachers of instructional technologies self-efficacy levels. Procedia-Social and Behavioral Sciences, 28, 499-502. https:/ / doi.org/10.1016/j.sbspro.2011.11.096

Zelkowski, J., Gleason, J., Cox, D. C., \& Bismark, S. (2013). Developing and Validating a Reliable TPACK Instrument for Secondary Mathematics Preservice Teachers. Journal of Research on Technology in Education, 46(2), 173-206. https:/ / doi.org/10.1080/15391523.2013.10782618

\section{http://www.ejmste.com}

